\title{
Wicherhamomyces anomalus biofilm supported on wood husk for chromium wastewater treatment
}

\author{
Meryem Asri $^{\mathrm{a}}$, Naïma El Ghachtouli ${ }^{\mathrm{a}, *}$, Soumya Elabed ${ }^{\mathrm{a}}$, Saad Ibnsouda Koraichi ${ }^{\mathrm{a}, \mathrm{b}}$, Alae Elabed ${ }^{\mathrm{a}}$, \\ Bruna Silva ${ }^{c}$, Teresa Tavares ${ }^{c}$ \\ ${ }^{a}$ Laboratoire de Biotechnologie Microbienne, Faculté des Sciences et Techniques, Université Sidi Mohamed Ben Abdellah, Fès, Morocco \\ ${ }^{\mathrm{b}}$ Centre Universitaire Régional d'Interface, Université Sidi Mohamed Ben Abdellah, Fès, Morocco \\ ${ }^{c}$ CEB-IBB- Centre of Biological Engineering, Institute for Biotechnology and Bioengineering, University of Minho, Campus de Gualtar, $4710-057$ Braga, Portugal
}

\section{A R T I C L E I N F O}

\section{Keywords:}

Chromium

Biofilm

Biosorption

Yeast

Wood husk

\begin{abstract}
A B S T R A C T
A Wickeramomyces anomalus biofilm supported on wood husk was used to remediate water bodies contaminated with chromium (Cr), in batch and open systems. The favorable adhesion ability of the chromium-resistant yeast strain on the wood husk was predicted by XDLVO theory and confirmed by environmental scanning electronic microscopy. The chromium decontamination was then optimized in a batch mode using a central composite design (CCD). Analysis of variance (ANOVA) showed a high coefficient of determination ( $\mathrm{R}^{2}$ ) value of $0.93-0.91$ for $\mathrm{Cr}(\mathrm{VI})$ and total $\mathrm{Cr}$ removal, respectively, ensuring a satisfactory fitting of the second-order regression model to the experimental data. In batch system, the concentration of biomass exhibited the minimal effect on the process. An acidic $\mathrm{pH}$ of 3.72 and 5.48, an initial chromium concentration of 10 and $16.91 \mathrm{mg} / \mathrm{L}$ and a support dose of 6.95 and $8.20 \mathrm{~g} / \mathrm{L}$ were optimal for $\mathrm{Cr}(\mathrm{VI})$ and total $\mathrm{Cr}$ removal, respectively. The breakthrough curves were determined in open system for different initial chromium concentrations. The study of glucose concentration effect on the yeast extracellular polymeric substances (EPS) production showed that a medium exempt of glucose allowed maximal EPS production and minimal chromium removal efficiency, while $20 \mathrm{~g} / \mathrm{L}$ glucose concentration of presented the optimal condition for chromium removal.
\end{abstract}

\section{Introduction}

Toxic heavy metals are the most harmful pollutants increasingly produced by natural and anthropogenic means [1]. Chromium is one of the main pollutants discharged in the environment due to its extensive use in various industries [2,3]. It occurs in different degrees of toxicity depending on its oxidation state. Cr (III) and hexavalent $\mathrm{Cr}$ (VI) forms are of significant concern in environmental issues [4].

Hexavalent chromium $\mathrm{Cr}(\mathrm{VI})$ is a highly toxic water pollutant. It can originate from different anthropogenic activities such as leather tanning, pigment synthesis, electroplating and metal finishing. Chromiumcontaminated wastewaters directly discharged into the environment cause serious threat to human beings and present harmful ecological effects [5].

The United States Environmental Protection Agency determined the value of $0.1 \mathrm{mg} / \mathrm{L}$ as a maximum contaminant level for total chromium in the environment. Hence, chromium removal is gaining importance in the environmental research community [6].
In order to alleviate water stress, there is a pressing need to seek suitable technological systems for effective metal recovery before the discharge of contaminated wastewater. Owing to its numerous advantages, biosorption has aroused a great interest. It has been defined as the ability of biomaterials to selectively bind ions or molecules from aqueous solutions [7]. It is considered as a cost-effective and efficient method for chromium removal from aqueous environment [8-10].

Recently, biofilm-based biosorption is considered as an attractive process that has been used effectively for metals removal from industrial effluents [11-13]. This technology involved different materials as a support for microbial cells attachment $[14,15]$. Among these materials, wood husk was successfully reported for remediation application [14]. This material is known to have a great ability to attach microbial cells, providing also a source of cellulose for these ones [16]. Biofilm adhesion is a crucial step for biofilm formation [17]. It was reported that the biofilm attachment during its functional life time is a key factor for its performance, since it assures the long-term stability of the system [18].

\footnotetext{
* Corresponding author at: Laboratoire de Biotechnologie Microbienne, Faculté des Sciences et Techniques, Université Sidi Mohamed Ben Abdellah, Route Immouzer, P.O. Box 2202, Fez, Morocco.

E-mail address: naima.elghachtouli@usmba.ac.ma (N. El Ghachtouli).
} 
Among theoretical models of adhesion prediction, XDLVO theory remains a reliable tool for the evaluation of the biofilm initial attachment capacity, taking into account Van der Waals and acid-basic interactions. Numerous reports have proved its ability to describe microbial adhesion to different solid surfaces $[17,19]$.

In the biofilm growth mode, microbial cells are immobilized in a heterogeneous layer of extracellular polymeric substances (EPS). It refers to polysaccharides, proteins, nucleic acids and other biopolymers located outside the cell [20]. The natural ability of cells to produce these substances is a major element in biofilm formation [21].

Some works have reported the major role of EPS in the sorption of inorganic substances. In fact, the application of the microbial EPS in heavy metals biosorption and immobilization was extensively reported [21-23]. The production of these biopolymers is mainly influenced by the substrate type, nutrient content and external conditions [23].

Experimental design is a useful tool allowing the optimization of a process conditions while studying the possible interactions between numerous influencing variables at limited number of experimental trials [24]. It is a methodological strategy, widely performed in experiments influenced by several variables where it is necessary to evaluate the combined effect of the factors on a response [25,26]. The response surface methodology (RSM) is routinely used for the efficiency optimization of several industrial processes in order to study the combined influence of independent variables [4].

Thus, this study aims: (i) the evaluation of the theoritical adhesion ability of the Wickerhamomyces anomalus yeast strain to wood husk surface, using XDLVO predictive theory; (ii) the optimization of chromium removal by the biofilm in batch system using central composite experimental design; (iii) the determination of breakthrough curves in open system under different initial chromium concentrations and (iv) the evaluation of extracellular polymeric substances production under different glucose concentrations.

\section{Materials and methods}

\subsection{Yeast strain and growing conditions}

A Chromium resistant and removing yeast Wickerhamomyces anomalus previously isolated from wastewater samples, contaminated with chemical industrial wastes including those from tanning processing in Fez, Morocco, was used in this study. It was seeded on yeast medium agar ( $1 \%$ peptone, $1 \%$ yeast extract, $2 \%$ glucose and $1.5 \%$ agar) plates and incubated for $48 \mathrm{~h}$ at optimal temperature of $30{ }^{\circ} \mathrm{C}$. The yeast strain showed a $\mathrm{Cr}(\mathrm{VI})$ adsorption capacity of $28.14 \mathrm{mg}$. $\mathrm{Cr}(\mathrm{VI})$ $\mathrm{g}^{-1}$ and a removal percentage of $100 \%$ at the optimal $\mathrm{pH}$ value of 4 [7].

\subsection{Preparation of the support}

Wood husk was obtained from a local wood industry. It was extensively washed under tap water in order to remove any particulate and sprayed with distilled water. This material was crushed, dried at $60{ }^{\circ} \mathrm{C}$ and sieved through a $1-5 \mathrm{~mm}$ size before further usage.

\subsection{Contact angle measurements CAM)}

Preparation of yeast strains suspension for cell surface CAM was carried out following the protocol of [27] with slight modifications as described by [28]. Microbial lawns suitable for CAM were prepared as described by [16] and realized in triplicate with separately cultured microbes.

\subsubsection{Hydrophobicity}

According to Vogler's approach [29], the value of water contact angle $\theta_{\mathrm{W}}$ permits to evaluate the hydrophobicity of a surface qualitatively. A $\theta_{\mathrm{W}}$ value higher than $65^{\circ}$ indicates a hydrophobic surface, conversely a $\theta_{\mathrm{W}}$ value lower than $65^{\circ}$ allows classifying a surface as being hydrophilic.

By contrast, Van Oss approach seems to be more precise. It permits the determination of the absolute degree of hydrophobicity of a surface which is calculated using Eq. (1).

In this approach, the degree of hydrophobicity of a given material (i) is expressed as the free energy of interaction between two identical surfaces immersed in water ( $\Delta$ Giwi). If the interaction between the two surfaces is stronger than the interaction between each surface with water $(\Delta G \mathrm{iwi}<0)$, the surface is considered hydrophobic and conversely $(\Delta G$ iwi $>0)$, the surface is considered hydrophilic.

$$
\begin{aligned}
\Delta \text { Giwi }= & -2 \gamma_{i w}=-2\left[\left(\left(\gamma_{i}^{L W}\right)^{1 / 2}-\left(\gamma_{w}^{L W}\right)^{1 / 2}\right)^{2}\right. \\
& \left.+2\left(\left(\gamma_{i}^{+} \gamma_{i}^{-}\right)^{1 / 2}+\left(\gamma_{w}^{+} \gamma_{w}^{-}\right)^{1 / 2}-\left(\gamma_{i}^{+} \gamma_{w}^{+}\right)^{1 / 2}\right)-\left(\gamma_{w}^{+} \gamma_{i}^{-}\right)^{1 / 2}\right]
\end{aligned}
$$

$\gamma_{i}{ }^{L W}$ is the Lifshitz-van der Waals component, $\gamma_{w}{ }^{L W}$ is the Lifshitzvan der Waals component of water, $\gamma \mathrm{i}^{+}$is the electron acceptor of a given material (i), $\gamma \mathbf{i}-$ is the electron donor of a given material (i), $\gamma_{w}{ }^{+}$ is the electron acceptor of water and $\gamma_{w}$-is the electron donor of water.

\subsubsection{Surface tension components}

Once the contact angles were measured, the Lifshitz-van der Waals $\left(\gamma^{\mathrm{LW}}\right)$ and acid-base $\left(\gamma^{\mathrm{AB}}\right)$ surface tension components were obtained using the three equation system obtained from the application of the Young-Dupré equation to each probe liquid [30], by using three different liquids with known surface parameters values $\gamma_{1}{ }^{\mathrm{LW}}, \gamma_{1}{ }^{+}$, and $\gamma_{1}{ }^{-}$, for example water, formamide and diiodomethane (Table1). The unknown surface tension components of a solid surface $\left(\gamma_{s}{ }^{\mathrm{LW}}, \gamma_{\mathrm{s}}{ }^{+}\right.$, and $\left.\gamma_{\mathrm{s}}{ }^{-}\right)$or microbial surface $\left(\gamma^{\mathrm{LW}}, \gamma^{+}\right.$, and $\left.\gamma^{-}\right)$can be estimated.

$\gamma_{L}(\cos \theta+1)=2\left[\left(\gamma_{s}^{L W} \gamma_{L}^{L W}\right)^{1 / 2}+\left(\gamma_{s}^{+} \gamma_{L}^{-}\right)^{1 / 2}+\left(\gamma_{s}^{-} \gamma_{L}^{+}\right)^{1 / 2}\right]$

In this equation, $\theta$ is the measured contact angle and the subscripts (S) and (L) report to solid and liquid phases, respectively. $\gamma^{\mathrm{LW}}$ is the Lifshitz-van der Waals component of the surface free energy, $\gamma^{+}$and $\gamma^{-}$ are the electron acceptor and electron donor parameters, respectively, of the Lewis acid-base component $\left(\gamma^{\mathrm{AB}}\right)$. The surface free energy is expressed as: $\gamma_{\mathrm{S}}=\gamma_{\mathrm{S}}^{\mathrm{LW}}+\gamma_{\mathrm{S}}^{\mathrm{AB}}$ where $\gamma_{S}^{A B}=2\left(\gamma_{S}^{-} \gamma_{S}^{+}\right)^{1 / 2}$ is the acid-base free energy component.

2.3.3. Calculation of free energy adhesion of the yeast strain to wood surface by XDLVO theory

In the XDLVO approach the total interaction energy between microbial cells (m) and substratum (s) through water (w) is described as a balance between attractive Lifshitz-van der Waals forces, repulsive or attractive electrostatic forces and acid-base interaction forces, being written as:

$\Delta G^{\mathrm{XDLVO}}(\mathrm{d})=\Delta G^{\mathrm{LW}}(\mathrm{d})+\Delta G^{\mathrm{EL}}(\mathrm{d})+\Delta G^{\mathrm{AB}}(\mathrm{d})$

In this equation:

$\mathrm{d}$ : the separation distance between a cell and a substratum

$$
\begin{aligned}
\Delta G^{L W}= & \left(\left(\gamma_{M}^{L W}\right)^{1 / 2}-\left(\gamma_{S}^{L W}\right)^{1 / 2}\right)^{2}-\left(\left(\gamma_{M}^{L W}\right)^{1 / 2}-\left(\gamma_{L}^{L W}\right)^{1 / 2}\right)^{2} \\
& -\left(\left(\gamma_{S}^{L W}\right)^{1 / 2}-\left(\gamma_{L}^{L W}\right)^{1 / 2}\right)^{2}
\end{aligned}
$$

and

Table 1

Independent variables and levels considered for the removal of $\mathrm{Cr}$ (VI) and tot Cr using central composite design (CCD).

\begin{tabular}{llllllll}
\hline \multirow{2}{*}{ Variable } & \multirow{2}{*}{ Symbol } & \multicolumn{5}{l}{ Coded variable levels } \\
\cline { 3 - 7 } & & & $-\alpha$ & -1 & 0 & 1 & $+\alpha$ \\
\cline { 3 - 7 } & & $\mathrm{x} 1$ & 2 & 2 & 5 & 8 & 8 \\
$\mathrm{pH}$ & $\mathrm{x} 2$ & 10 & 10 & 55.5 & 100 & 100 \\
Initial Cr(VI) concentration (mg/L) & & & & & \\
Biomass concentration (g/L) & $\mathrm{x} 3$ & 1 & 1 & 3 & 5 & 5 \\
Support dose (g/L) & $\mathrm{x} 4$ & 0.5 & 0.5 & 5.25 & 10 & 10
\end{tabular}




$$
\begin{aligned}
\Delta G^{A B}= & 2\left[\left(\gamma_{L}^{+}\right)^{1 / 2}\left(\left(\gamma_{M}^{-}\right)^{1 / 2}+\left(\gamma_{S}^{-}\right)^{1 / 2}-\left(\gamma_{L}^{-}\right)^{1 / 2}\right)\right. \\
& \left.+\left(\gamma_{L}^{-}\right)^{1 / 2}\left(\left(\left(\gamma_{M}^{+}\right)^{1 / 2}+\left(\gamma_{S}^{+}\right)^{1 / 2}-\left(\gamma_{L}^{+}\right)^{1 / 2}\right)-\left(\gamma_{L}^{-} \gamma_{S}^{+}\right)^{1 / 2}\right)-\left(\gamma_{L}^{+} \gamma_{S}^{-}\right)^{1 / 2}\right]
\end{aligned}
$$

The usage of a suspension liquid with high ionic strength $\left(\mathrm{KNO}_{3}\right.$ $0.1 \mathrm{M}$ ) allows the negligence of electrostatic interaction free energy $\Delta \mathrm{G}^{\mathrm{EL}}$ as done before [31,32].

\subsection{Batch system assays}

\subsubsection{Biosorption experiments}

All laboratory glassware was washed twice with deionized waster after being soaked in nitric acid $(60 \%, \mathrm{v} / \mathrm{v})$ bath overnight.

Yeast strain growth was obtained at $30^{\circ} \mathrm{C}$ using YPG on a rotary shaker at $130 \mathrm{rpm}$. After $24 \mathrm{~h}$ of incubation, yeast cells were harvested by centrifugation at $7000 \mathrm{~g}$ for $10 \mathrm{~min}$.

Batch experiments were performed in modified YPG medium $(0.2 \%$ peptone, $0.2 \%$ yeast extract, $2 \%$ glucose) prepared with sterile distilled water as proposed by [7]. The medium contained different initial concentrations $(10,55,100 \mathrm{mg} / \mathrm{L})$ of $\mathrm{Cr}(\mathrm{VI})$ as $\mathrm{K}_{2} \mathrm{Cr}_{2} \mathrm{O}_{7}$ and final solution $\mathrm{pH}$ was adjusted to 2,5 or 8 by adding either $0.1 \mathrm{M} \mathrm{HCl}$ or $0.1 \mathrm{M}$ $\mathrm{NaOH}$. An uninoculated medium prepared strictly using the same procedures served as a control to determine the extent of abiotic $\mathrm{Cr}(\mathrm{VI})$ reduction. Yeast biomass was supported on different wood husk amounts $(0.5,5.25,10 \mathrm{~g} / \mathrm{L})$ and some other assays were also carried out with different concentrations of biomass (1, 3, $5 \mathrm{~g} / \mathrm{L})$. Experiments were conducted in 250 Erlenmeyer flasks with continuous stirring (130 rpm) in a shaker incubator at $30^{\circ} \mathrm{C}$ [33]. Aliquots of $1 \mathrm{ml}$ were taken periodically, centrifuged and residual $\mathrm{Cr}(\mathrm{VI})$ concentration was determined by colorimetry using the diphenylcarbazide method [34]. The biosorption potential percentage was calculated as:

Biosorption potential\%

$=\frac{\text { (Initial concentration of } \mathrm{Cr}-\text { Observed concentration of } \mathrm{Cr} \text { ) } \mathrm{x} 100}{\text { Initial concentration of } \mathrm{Cr}}$

The total $\mathrm{Cr}$ in samples was quantified by inductive coupled plasma, ICP-OES (Optima 8000, Perkin-Elmer), at wavelength $283.5 \mathrm{~nm}$ using argon gas as the fuel.

\subsubsection{Central composite design (CCD)}

A 4 factor-5-level design, in which five coded levels were assigned to each factor (Table 1) was selected. The arrangement of central composite design is shown in Table 2 [26].

Statistical analysis and model fitting: The experimental data (Table 2) were subjected to a regression analysis to be fitted by a second-order polynomial model Eq. (5) describing the relationship between the studied factors and the responses.

$Y=b_{0}^{\prime}+\sum_{i=1}^{n} b_{i} X_{i}+\sum_{i=1}^{n} b_{i i} X_{i}^{2}+\sum_{i=1}^{n} \sum_{j>1}^{n} b_{i j} X_{i} X_{j}$

In here, $\mathrm{Y}$ is the predicted response, $\mathrm{b}_{0}$ is the constant coefficient, $\mathrm{b}_{\mathrm{i}}$ is the linear coefficient, $b_{i j}$ is the interaction coefficient, $b_{i i}$ coded values are the quadratic coefficient, and $\mathrm{X}$ are the process factors.

The analysis of variance (ANOVA) was also done to determine the significance of each factor in the fitting model and to determine the goodness of the fit. For this purpose, the software SAS.JMP v 8.0.1 (trial version) has been used. Graphical representation of the fitting polynomial has been given in the form of 3D plots.

\subsection{Open system assays}

The open-system assays were performed in plexiglas columns (height: $33 \mathrm{~cm}$, internal $\varnothing 3.5 \mathrm{~cm}$ ) filled with $96 \mathrm{~cm}^{3}$ of wood husk supporting a $W$. anomalus biofilm, while a control assay column was filled only with wood husk.
Table 2

Arrangement of the central composite design for independent variables $(\mathrm{pH}$ $(\mathrm{x} 1)$, initial chromium concentration (x2), biomass concentration (x3), support

\begin{tabular}{|c|c|c|c|c|}
\hline \multirow[t]{2}{*}{ Experiment no. } & \multicolumn{4}{|c|}{ Variable values } \\
\hline & $\mathrm{x} 1$ & $\mathrm{x} 2$ & $\mathrm{x} 3$ & $\mathrm{x} 4$ \\
\hline 1 & 2 & 10 & 5 & 0,5 \\
\hline 2 & 2 & 10 & 1 & 10 \\
\hline 3 & 2 & 10 & 5 & 10 \\
\hline 4 & 2 & 100 & 5 & 10 \\
\hline 5 & 2 & 10 & 1 & 0,5 \\
\hline 6 & 2 & 100 & 1 & 0,5 \\
\hline 7 & 2 & 55 & 3 & 5,25 \\
\hline 8 & 2 & 100 & 1 & 10 \\
\hline 9 & 2 & 100 & 5 & 0,5 \\
\hline 10 & 8 & 10 & 5 & 0,5 \\
\hline 11 & 8 & 100 & 1 & 0,5 \\
\hline 12 & 8 & 10 & 5 & 10 \\
\hline 13 & 8 & 10 & 1 & 0,5 \\
\hline 14 & 8 & 55 & 3 & 5,25 \\
\hline 15 & 8 & 100 & 5 & 10 \\
\hline 16 & 8 & 100 & 1 & 10 \\
\hline 17 & 8 & 100 & 5 & 0,5 \\
\hline 18 & 8 & 10 & 1 & 10 \\
\hline 19 & 5 & 55 & 3 & 10 \\
\hline 20 & 5 & 55 & 3 & 0,5 \\
\hline 21 & 5 & 55 & 5 & 5,25 \\
\hline 22 & 5 & 100 & 3 & 5,25 \\
\hline 23 & 5 & 10 & 3 & 5,25 \\
\hline 24 & 5 & 55 & 1 & 5,25 \\
\hline 25 (cp) & 5 & 55 & 3 & 5,25 \\
\hline 26 (cp) & 5 & 55 & 3 & 5,25 \\
\hline
\end{tabular}
dose (x4)).

The biofilm attachment on wood husk was carried out following the protocol of [12]. Afterwards, the metal aqueous solutions with initial concentrations of $10,25,50$ and $100 \mathrm{mg} / \mathrm{L}$ were pumped through the columns with a flow rate of $5 \mathrm{~mL} / \mathrm{min}$ and $\mathrm{pH}$ between 3.72 and 5.48 (optimum conditions according to experimental design). The total chromium and $\mathrm{Cr}(\mathrm{VI})$ concentrations in the outflow were periodically evaluated, as described above.

\subsection{Quantification of polysaccharides}

In order to evaluate the effect of glucose on extracellular polymeric substances production and $\mathrm{Cr}(\mathrm{VI})$ removal potential by yeast biofilm supported on wood husk, YPG-modified medium containing different glucose concentrations $(0,5,10,15,20 \mathrm{~g} / \mathrm{L})$ were pumped during the open system assays. The quantification of polysaccharides was realized following the protocol of [34]. The $\mathrm{Cr}(\mathrm{VI})$ removal percentage was measured as previously described, at an initial chromium concentration of $25 \mathrm{mg} / \mathrm{L}$.

\section{Results and discussion}

\subsection{Physicochemical surface characteristics of wood husk and $W$.} anomalus cells

\subsubsection{Wood husk surface characteristics}

Wood is a porous material, favorable for capillary penetration and microbial attachment. This material is characterized by a wide heterogeneity of its surface. Its roughness makes the liquid spreading more pronounced parallel than perpendicular to the wood grains orientation [35]. Wood is generally composed of cellulose (37-51\%), lignin (20-30\%), hemicellulose (20-30\%) and extractives (1-5.5\%) [36]. The extractives are not evenly distributed within the cell walls. Although their amount is very low in comparison to the other components of wood, they significantly affect the wettability of the material [36,37].

Wood husk is an available material, choosen to be the yeast 
Table 3

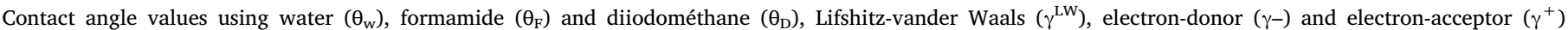
parameters, surface energies ( $\Delta$ Giwi) of wood husk and $W$. anomalus and the total energy of adhesion between yeast cells and the support $\left(\Delta \mathrm{G}^{\mathrm{XDLVO}}\right.$ ).

\begin{tabular}{|c|c|c|c|c|c|c|c|c|}
\hline \multirow[t]{2}{*}{ Material } & \multicolumn{3}{|c|}{ Contact angles $\left({ }^{\circ}\right)$} & \multicolumn{3}{|c|}{ Surface tension: components and parameters $\left(\mathrm{mJ} / \mathrm{m}^{2}\right)$} & \multirow{2}{*}{$\begin{array}{l}\text { Surface } \\
\text { energies } \\
\Delta G \text { iwi (mJ/ } \\
\mathrm{m}^{2} \text { ) }\end{array}$} & \multirow{2}{*}{$\begin{array}{l}\text { Interaction free energy } \Delta G^{\text {XDLVO }} \\
\left(\mathrm{mJ} / \mathrm{m}^{2}\right)\end{array}$} \\
\hline & $\theta_{\mathrm{w}}$ & $\theta_{\mathrm{F}}$ & $\theta_{\mathrm{D}}$ & $\gamma^{\mathrm{LW}}$ & $\gamma^{+}$ & $\gamma-$ & & \\
\hline Wood husk & $81.46 \pm 0.32$ & $61.73 \pm 1.70$ & $51.13 \pm 1.00$ & $33.57 \pm 0.18$ & $029 \pm 0.18$ & $6.28 \pm 1.56$ & $\begin{array}{l}-49.27 \pm \\
386\end{array}$ & -7.13 \\
\hline W. anomalus & $23.8 \pm 2.72$ & $28.6 \pm 1.70$ & $30.9 \pm 0.32$ & $43.74 \pm 0.28$ & $0.13 \pm 0.08$ & $54.58 \pm 1.19$ & $\begin{array}{l}36.27 \pm \\
2.48\end{array}$ & \\
\hline
\end{tabular}

attachment support. Wood may be a good support for different biofilms especially for microbes able to breakdown wood macropolymers and to use lignin-related products as nutrients [18]. It is a porous material offering a high surface area for microbial attachement. Furthermore, wood husk contains a relevant amount of glucose within cellulose. Thus, it contains easily substituted hydroxyl groups providing a weakly basic and acidic ion exchange condition, favorable to microbial attachment and growth $[14,38]$. The small particle size of the used wood husk ( $1-5 \mathrm{~mm})$ provides high specific surface area for microbial attachment.

Wood surface characterization was the topic of numerous research works $[16,36,39]$. Its surface free energy presents a wide range of variation in litterature due to the chemical heterogenity and biodiversity of wood species [36].

The used wood husk exhibits a negative surface free energy value of $-49,27 \pm 386 \mathrm{~mJ} / \mathrm{m}^{2}$, a $\gamma^{-}$value of $6.28 \pm 1.56 \mathrm{~mJ} / \mathrm{m}^{2}$ and $\gamma^{+}$ value of $029 \pm 0.18 \mathrm{~mJ} / \mathrm{m}^{2}$ (Table 3). These findings are in line with other data found in previous works [16], where the wood surface exhibited an hydrophobic caracter, a strong electron-donor component and a weak electron-acceptor component. It was reported that the electron-acceptor component of wood results from the acidic hydrogen atoms on its macromolecules, mainly carboxylic acids and phenolic functions of hemicellulose and lignin, while its electron-donor component $(\gamma-)$ is related to the oxygen/carbon ratio of lignin and polysaccharides present in wood [39].

\subsubsection{W. anomalus cells surface characteristics}

W. anomalus cells exhibited hydrophilic character with a $\theta \mathrm{w}$ of $23.8^{\circ} \pm 2.72$ and a $\Delta$ Giwi of $36.27 \pm 2.48 \mathrm{~mJ} / \mathrm{m}^{2}$ (Table 3 ). These findings agree with previous results reporting the hydrophilic caracter of yeast cells $[40,41]$. Yeast surface hydrophobicity has been shown to be related to surface protein concentration [42-44].

$W$. anomalus cells appear to behave predominantly as electron donors/Lewis bases with high values of $\gamma-, 54.58 \pm 1.19 \mathrm{~mJ} / \mathrm{m}^{2}$. A previous study showed that microbial cell surfaces are mainly electron donating, while electron-accepting cell surfaces are rarely found [45]. This character may be attributed to the presence of phosphate groups in their wall [44], as suggested before by [46]. Previous FTIR analyses of $W$. anomalus confirm the presence of phosphate groups on its cell surface [33].

\subsection{Free energy adhesion of the yeast strains to wood species by XDLVO theory}

The use of biofilm reactors for wastewater treatment is becoming a common application of environmental biotechnology. However, studies dealing with the stability of these systems as a function of the supportcells compatibility are still very few.

The attachment of microbial cells to a solid surface is the first and most important stage of the biofilm formation [47,48]. A good control of the interactions between microbial cells and their support within the biofilm system is of extreme importance to assure its long-term stability [18].
On this basis, the adhesion ability between the yeast strain and the support was first considered theoretically and experimentally evaluated. Many efforts were oriented to understand the biofilm formation on solid surfaces, either to prevent harmful biofilms formation or to control useful biofilms in biotechnological applications such as wastewater treatment.

Among theoretical models of adhesion prediction, XDLVO theory remains a reliable tool for the evaluation of the biofilm initial attachment, taking into account Van der Waals and acid-basic interactions. Numerous reports have proved its ability to describe microbial adhesion to different solid surfaces $[17,19]$.

The XDLVO predictions of the free energy of adhesion between yeast strain and wood husk is presented in Table 3. According to this theory, positive values of the $\Delta \mathrm{G}^{\mathrm{XDLVO}}$ indicate unfavorable adhesion or repulsion. On the opposite, attraction between two interacting surfaces occurs when the total energy values $\Delta \mathrm{G}^{\mathrm{XDLVO}}$ are negative. In the present case, a negative total energy value $\Delta \mathrm{G}^{\mathrm{XDLVO}}$ of $-7.13 \mathrm{~mJ} / \mathrm{m}^{2}$ was obtained, showing a favorable adhesion within the biofilm system. environmental scanning electronic microscopy images on Fig. 1, show the cellulose porous structure offering a high surface area for microbial adhesion and confirm the favorable attachment of yeast cells to wood husk.

\subsection{Optimisation of chromium biosorption in batch system}

The influence of four factors (medium $\mathrm{pH}$, initial $\mathrm{Cr}$ concentration, biomass concentration and support dose) on measurable responses $(\mathrm{Cr}$ (VI) (y1) and total $\mathrm{Cr}$ (y2) removal percentage at equilibrium) was studied. For CDD assays, YPG-modified medium was used as previously suggested by [7]. Indeed, the use of a rich medium may cause an interference between the components which reduces the number of available sites for metals uptake.

The study intervals were set from the preliminary experiments. Table 2 shows the arrangement of central composite design experiments allowing the development of the appropriate empirical equations. Additional experiments were carried out at the centre point to estimate the overall error.

Using SAS JMP v 8.0.1 program, experimental data were fitted by a second-order model relating $\mathrm{Cr}(\mathrm{VI})$ removal percentage at equilibrium (y1) and total $\mathrm{Cr}$ removal percentage at equilibrium $\left(\mathrm{y}_{2}\right)$ to the factors.

The models were described according to Eq. (6) as follows:

$Y_{1}=85.28-19.92 X_{1}-12.16 X_{2}+0.69 X_{3}+7.80 X_{4}-7.24 X_{1} X_{2}-0.18$

$X_{1} X_{3}-0.006 X_{2} X_{3}+0.68 X_{1} X_{4}+3.49 X_{2} X_{4}+1.91 X_{3} X_{4}$

$-14.85 X_{1}^{2}+4.07 X_{2}^{2}+7.48 X_{3}^{2}-8.28 X_{4}^{2}$

$Y_{2}=65.61-1.03 X_{1}-2.13 X_{2}+1.54 X_{3}+11.13 X_{4}-7.89 X_{1} X_{2}+1.33$

$X_{1} X_{3}-0.43 X_{2} X_{3}+7.28 X_{1} X_{4}+1.06 X_{2} X_{4}+1.26 X_{3} X_{4}$

$-38.79 X_{1}^{2}+2.58 X_{2}^{2}+5.88 X_{3}^{2}-9.93 X_{4}^{2}$

The results were then analyzed by ANOVA to assess the goodness of the fit. Statistical parameters obtained from the ANOVA for the reduced 

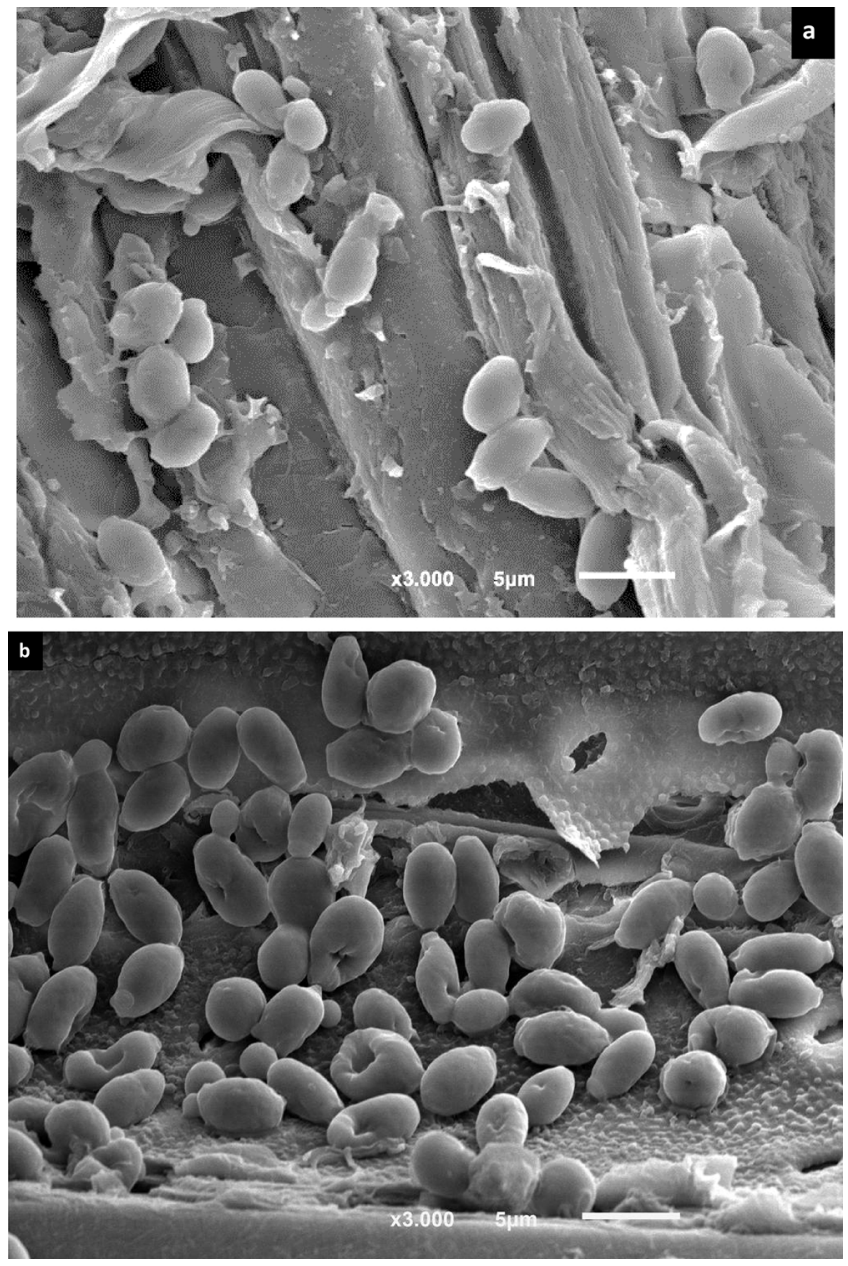

Fig. 1. SEM of W. anomalus on wood husk $(3000 \times)$. (a) Control yeast cells; (b) Metal loaded cells at initial concentration $25 \mathrm{mg} / \mathrm{L}$.

models of chromium removal are given in Tables 4 and 5. Analysis of variance (ANOVA) showed a high coefficient of determination $\left(\mathrm{R}^{2}\right)$ value of 0.93 and 0.91 for $\mathrm{Cr}(\mathrm{VI})$ and total $\mathrm{Cr}$ respectively, ensuring a satisfactory fitting of the second-order regression model to the experimental data.
Table 5

Analysis of variance for the reduced models of $\mathrm{Cr}(\mathrm{VI})$ and tot $\mathrm{Cr}$ removal.

\begin{tabular}{lll}
\hline Variable & $\% \mathrm{Cr}(\mathrm{VI})$ removal & \% tot Cr removal \\
\hline$R^{2}$ & 0.925562 & 0.9137 \\
$R^{2}$ adj & 0.830824 & 0.8039 \\
df & 14 & 14 \\
$F_{\text {exp }}$ & 9.7696 & 8.3245 \\
Prob $>F$ & $0.0003^{* * *}$ & $0.0006^{* * *}$ \\
Std. Dev. & 9.825378 & 11.30101 \\
\hline
\end{tabular}

$* F_{\exp }$ defined as the ratio of the mean square of the model to mean square of the error.

\subsubsection{Effect of $p H$}

Many works have confirmed that the biosorption was $\mathrm{pH}$ dependant $[7,49]$. In this study, acidic medium $\mathrm{pH}$ values were optimal for chromium removal by yeast biofilm. A pH of 3.72 was optimal for $\mathrm{Cr}(\mathrm{VI})$ removal and a pH of 5.48 was optimal for total $\mathrm{Cr}$ removal. It is known that in general low $\mathrm{pH}$ values enhance $\mathrm{Cr}(\mathrm{VI})$ biosorption from aqueous solutions $[7,12]$. Indeed, at high $\mathrm{pH}$ values the overall surface charge of the biomass becomes negative. This negative charge would generate repulsive forces towards chromate ions, appearing as anions $\left(\mathrm{CrO}_{4}{ }^{2-}\right.$ or $\mathrm{Cr}_{2} \mathrm{O}_{7}{ }^{2-}$ ) in aqueous surrounding environment, while acidic solutions offer a positive overall charge to the microbial surface, promoting $\mathrm{Cr}$ (VI) anionic species binding to positively charged functional groups [50].

The study of interactions by the central composite design showed that the interactions between medium $\mathrm{pH}$ and $\mathrm{Cr}(\mathrm{VI})$ initial concentration displayed the most prominent effect on the responses. The response surface plots of the effect of this interaction on both responses are shown in the Fig. 2(a, b). The $\mathrm{pH}$ of the medium is absolutely a pertinent parameter in biosorption process, influencing the overall surface charge of the biomass by affecting the ionization states of functional groups on the biosorbent surface [51]. Moreover, $\mathrm{pH}$ was reported to strongly affect the chemistry of metalic ions in solution and their biosorption availability [52].

Depending on $\mathrm{pH}$, chromium may exhibit differents ionic species in aqueous solutions. Above $\mathrm{pH} 8.0, \mathrm{CrO}_{4}{ }^{2-}$ is the only chromium species present in solution. At $\mathrm{pH}$ range $2-6 \mathrm{HCrO}_{4}$ - and $\mathrm{Cr}_{2} \mathrm{O}_{7}{ }^{2-}$ ions are in equilibrium. At pH lower than $2.0 \mathrm{Cr}_{3} \mathrm{O}_{10}{ }^{2-}$ and $\mathrm{Cr}_{4} \mathrm{O}_{13}{ }^{2-}$ species are predominant [53].

\subsubsection{Effect of metal initial concentration}

The removal of chromium experiments were performed with $\mathrm{Cr}(\mathrm{VI})$ concentrations ranging from 10 to $100 \mathrm{mg} / \mathrm{L}$. Results showed that both

Table 4

Results of statistical central composite design analysis for Cr(VI) removal and tot Cr removal.

\begin{tabular}{|c|c|c|c|c|}
\hline & \multicolumn{2}{|l|}{ y1 } & \multicolumn{2}{|l|}{ y2 } \\
\hline & Coefficientestimate & P-value & Coefficientestimate & P-value \\
\hline Constant & 85.278714 & $<0.0001^{* * *}$ & 65.611857 & $<0.0001^{* * *}$ \\
\hline $\mathrm{x} 1$ & -19.91889 & $<0.0001^{* * *}$ & 1.0288889 & 0.7067 \\
\hline $\mathrm{x} 2$ & -12.15833 & $<0.0001^{* * *}$ & -2.132778 & 0.4403 \\
\hline $\mathrm{x} 3$ & 0.6922222 & 0.7706 & 1.5411111 & 0.5745 \\
\hline $\mathrm{x} 4$ & 7.8033333 & $0.0063^{* *}$ & 11.126667 & $0.0015^{* * *}$ \\
\hline $\mathrm{x} 1{ }^{*} \mathrm{x} 2$ & -7.240625 & $0.0133^{* *}$ & -7.894375 & $0.0175^{*}$ \\
\hline $\mathrm{x} 1$ * $\mathrm{x} 3$ & -0.183125 & 0.9419 & 1.328125 & 0.6475 \\
\hline $\mathrm{x} 2 * \mathrm{x} 3$ & -0.006875 & 0.9978 & -0.430625 & 0.8816 \\
\hline $\mathrm{x} 1$ * $\mathrm{x} 4$ & 0.679375 & 0.7872 & 7.284375 & $0.0257^{*}$ \\
\hline $\mathrm{x} 2 * \mathrm{x} 4$ & 3.485625 & 0.1836 & 1.055625 & 0.7158 \\
\hline $\mathrm{x} 3 * \mathrm{x} 4$ & 1.908125 & 0.4536 & 1.255625 & 0.6653 \\
\hline $\mathrm{x} 1$ * $\mathrm{x} 1$ & -14.84995 & $0.0341 *$ & -38.79748 & $0.0002^{* * *}$ \\
\hline $\mathrm{x} 2 * \mathrm{x} 2$ & 4.0750476 & 0.5205 & -2.582476 & 0.7215 \\
\hline$x 3 * x 3$ & 7.4800476 & 0.2486 & 5.8825238 & 0.4226 \\
\hline$x 4 * x 4$ & -8.279952 & 0.2046 & -9.927476 & 0.1874 \\
\hline
\end{tabular}

Level of statistical significance: ${ }^{*} \mathrm{P}<0.05 ; * * \mathrm{P}<0.01 ; * * * \mathrm{P}<0.001$. 

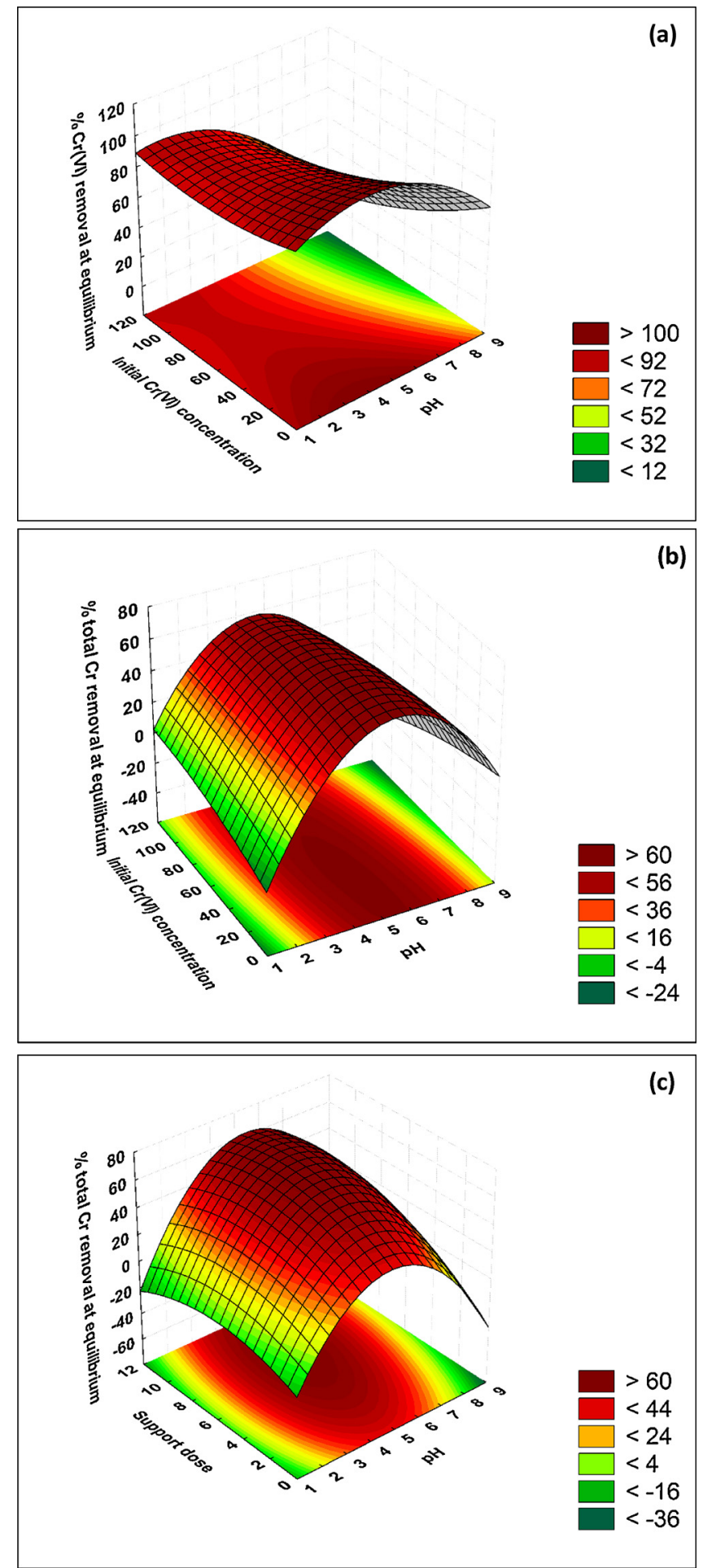

Fig. 2. Second-order response surface plot in the chromium removal ( $\mathrm{Cr}(\mathrm{VI})$ (y1) and total Cr (y2)) by $W$. anomalus biofilm on wood husk. Dependence of the responses on: (a) the medium $\mathrm{pH}(\mathrm{x} 1)$, (b) initial chromium concentration (x2) and (c) support dose (x4).

responses were strongly affected by initial chromium concentration. Thus, complete chromium removal percentage was obtained with the concentration of $10 \mathrm{mg} / \mathrm{L}$ and the removal efficiency decreased with the increase of the initial chromium concentration. These observations are in line with previous results showing a better efficiency at low initial metal concentrations [54]. This may be explained by surface saturation that occurs with the increase of initial metal concentrations. At low concentrations, available adsorption sites for chromium fixation are quickly occupied, while at higher concentrations, the slow metal ions diffusion into the biomass surface by intraparticle diffusion decreases chromium removal efficiency [55].

\subsubsection{Effect of biomass concentration}

Results of the experimental design showed that, out of the four tested factors, biomass concentration displayed the minimal effect on the process efficiency, at the opposite to planctonic form of the microbial cells assays where the biomass concentration affects strongly chromium removal efficiency [56]. Similar results were previously reported by [57] who stated that there is no evidence of correlation between wastewater treatment rate and dry biomass. In fact, biofilm systems are known to be complex and different parameters may influence their performance such as extracellular polymeric substances production, quorum sensing or metabolic pathways [58].

\subsubsection{Effect of support dose}

The support dose is one of the parameters that strongly affect the biosorption capacity within the biofilm system. The influence of the support dose on the biosorption capacity was studied for a concentration between 0.5 and $10 \mathrm{~g} / \mathrm{L}$ (Fig. 2c). The increase in the chromium removal percentage with the increase in the support dosage may be due to the increase of microbial attachment available area. It may also be due to the increase of the amount of glucose in the medium contained in this substratum within its cellulolytic composition, as a direct relation between glucose and chromium reduction was reported [38]:

$\mathrm{C}_{6} \mathrm{H}_{12} \mathrm{O}_{6}+8 \mathrm{CrO}_{4}^{2-}+34 \mathrm{H}^{+} \rightarrow 8 \mathrm{Cr}^{3+}+6 \mathrm{HCO}_{3}^{-}+20 \mathrm{H}_{2} \mathrm{O}$

\subsection{Open system assays}

In open systems filled with $W$. anomalus biofilm-coated wood husk, the results showed $\mathrm{Cr}(\mathrm{VI})$ retention percentages of 7.5, 19.9, 28.2 and $57.82 \%$ and total $\mathrm{Cr}$ retention percentages of 7.1, 15.7, 19.43 and $40.02 \%$ for the initial concentrations of $10,25,50$ and $100 \mathrm{mg} / \mathrm{L}$, respectively (Fig. 3a). Fig. 3b illustrates the resulting breakthrough curves of $\mathrm{Cr}(\mathrm{VI})$ removal at different inlet concentrations. The concentration of chromium in the effluent during the first few minutes approaches zero, but starts to increase rapidly with the exposition of the biomass to metal ions, until an equilibrium between retained concentration of metal and the concentration in the effluent is established after $18 \mathrm{~h}$. The retention capacity was strongly related to metal concentration, a higher percentage $(57.82 \%$ and $40.03 \%$ for $\mathrm{Cr}(\mathrm{VI})$ and total $\mathrm{Cr}$, respectively) of retained metal was observed with the highest chromium initial concentration $(100 \mathrm{mg} / \mathrm{L})$. This can be explained by the difference between the pollutant concentration in the solution and the pollutant concentration in the biosorbent, which is the main driving force conditioning the uptake process $[59,60]$.

The shape of biosorption curves is due to the formation of a mass transfer zone in the column. The metal uptake process by microbial cells is known to occur in two distinct phases, the first one being a passive transport period mainly related to the metal ions adsorption or ion exchange on microbial surfaces. This phase corresponds to a rapid increase in the uptake during the first hours of cell-metal contact, followed by an active uptake which is a slower process due to the metabolism of living cells [50]. When chromium solution contacts the fresh layer of the biomass, metal ions are sorbed onto the biomass fresh layer until the sorbed amount is in equilibrium with the influent concentration. At this moment, the biomass is loaded to its full capacity and that portion of the biomass becomes exhausted. Sorption is occurring above this line progressing in the direction of the flow and metal ions in the solution are actively transferred onto the biomass. The mass transfer zone will move down through the column until it reaches the effluent port and then the heavy metal concentration in the effluent starts to 

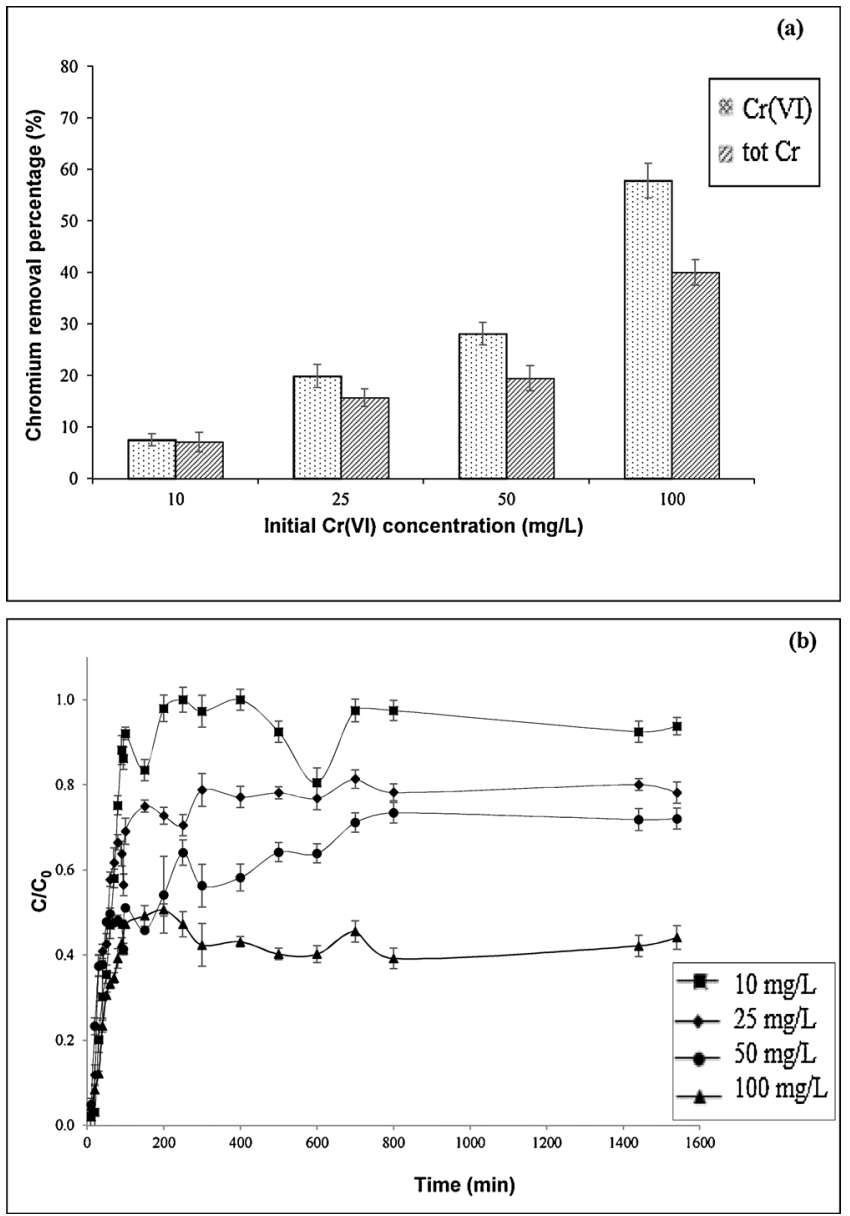

Fig. 3. (a) Breakthrough curves of $\mathrm{Cr}(\mathrm{VI})$ biosorption by W. anomalus biofilm supported on wood husk at different initial concentrations. (b) Uptake percentages obtained for column studies.

increase. In this process, the metallic solutions pass through the bed of active biomass, which would act as a series of batch contactors and consequently, the biomass would be loaded up to its maximum capacity [61].

The $\mathrm{Cr}(\mathrm{VI})$ may be reduced to the trivalent state by the biomass intervention following two different mechanisms. The first one considers that $\mathrm{Cr}(\mathrm{VI})$ is directly reduced by contact with electron-donor groups in microbial surface, particularly groups with lower reduction potential values than chromium $(+1.3 \mathrm{~V})$. The second mechanism considers the binding of chromium to the positively charged groups on the surface of biomass, where the adjacent electron-donor groups interfere to reduce $\mathrm{Cr}(\mathrm{VI})$ to $\mathrm{Cr}(\mathrm{III})$ which will be released in aqueous solutions due to electronic repulsion by the positive groups of the microbial surface. $\mathrm{Cr}$ (III) may also be complexed by microbial cells with adjacent Cr-binding groups [56].

\subsection{Extracellular polymeric substances production}

Extracellular polymeric substances (EPS) production is a common feature of many microbial cells. Research on microbial these substances has been mainly focused on bacterial species, whereas the EPS from yeast cells are especially more attractive due to their easier separation comparing to bacterial produced EPS [62].

Microbial EPS biosynthesis is likely stimulated in metallic solutions [63]. These saccharides offer a protective barrier against environmental stress conditions and hence increase the viability of microbial cells $[64,65]$. EPS matrix contains mainly sugars and mannuronic- and guluronic-acid complexes. It comprises also heteropolysaccharides,

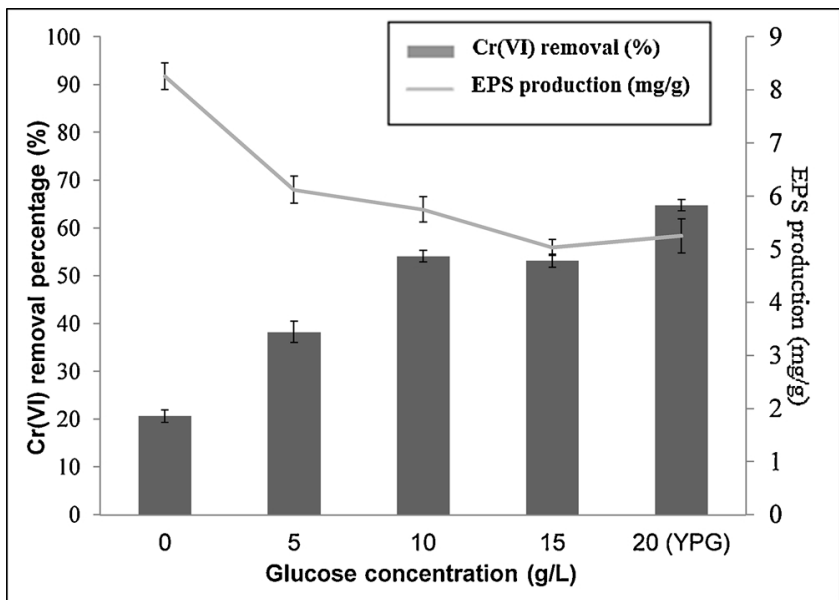

Fig. 4. Effect of glucose concentration on chromium removal and extracellular polymeric substances production by $W$. anomalus biofilm on wood husk.

proteins and nucleic acids [63,66]. The presence of carboxyl, hydroxyl and physphoryl functional groups is responsible for the negative charge of EPS. These groups are known to be involved in the metal uptake process by coordination, allowing the stability of ion polymer complexes [67].

EPS production has been the topic of numerous research works. Among the studied parameters, the culture medium composition can dramatically influence their production [68], especially glucose concentration in the medium proved to be of great impact [21].

Results in Fig. 4 show that the glucose-poor medium allowed a maximum EPS production $(826 \mathrm{mg} / \mathrm{g})$ but the lowest chromium removal $(20,64 \%)$. The chromium uptake increased with the increase of glucose concentration in the medium. A maximum chromium removal was obtained in the glucose rich medium $(20 \mathrm{~g} / \mathrm{L})$ with an uptake value of $64,8 \%$. Inversely, the EPS production decreased with the increase of the glucose concentration in the medium.

Our results show that rich medium was favorable for microbial growth and chromium removal but unfavored EPS production. Obtained data also show that the maximum chromium uptake was attained with the minimum EPS production. Hence, EPS production seems to have no effect on chromium uptake. In fact [69], showed previously that EPS production has no significant effect on chromium retention efficiency, as no relevant difference on the concentration of main binding sites such as carboxyl and phosphate was noted. [63] Reported also that the EPS layer presented a negative effect on metal uptake. Indeed, copper adsorption was higher by rinsed bacteria comparing to those with intact EPS. The negative effect of EPS layer on metal uptake may be due to aggregation effect that EPS induce within microbial cells, reducing the surface interactive area. In addition, the release of large quantities of dissolved organic carbon from the EPS layer may cause a metal complexation [69].

\section{Conclusion}

The biofilm of $W$. anomalus supported on wood husk demonstrated its ability to remove chromium from dilute solutions and its potential applicability in wastewater remediation. The biofilm formation ability was first predicted by XDLVO theory. The negative value of the free energy of adhesion is indicative of a good attachment of the yeast strain onto the wood surface. The theoretical prediction was confirmed by visualization of the experimental adhesion using environmental electronic microscopy.

A biosystem based of $W$. anomalus biofilm supported on wood husk, in batch system showed a great chromium removal potential. A scale-up into an open system was then evaluated and optimized. Both systems 
have proved the efficiency of the treatment and its biotechnological applicability for the remediation of chromium in aqueous solutions.

According to central composite design, the optimal conditions of $\mathrm{Cr}$ (VI) biosorption are $10 \mathrm{mg} / \mathrm{L}$ of $\mathrm{Cr}(\mathrm{VI})$ initial metal concentration, $\mathrm{pH}$ $3.72,5 \mathrm{~g} / \mathrm{L}$ of biomass and $6.95 \mathrm{~g} / \mathrm{L}$ of support. On the other hand, optimal conditions for total $\mathrm{Cr}$ removal are $16.91 \mathrm{mg} / \mathrm{L}$ of $\mathrm{Cr}(\mathrm{VI})$ initial metal concentration, $\mathrm{pH} 5.48,5 \mathrm{~g} / \mathrm{L}$ of biomass and $8.20 \mathrm{~g} / \mathrm{L}$ of support. The quantification of extracellular polymeric substances production related to the glucose concentration in the medium, showed that a glucose exempt medium allowed the maximal extracellular polymeric substances production but led to the minimal chromium removal efficiency.

\section{Acknowledgments}

This study was supported by the Portuguese Foundation for Science and Technology (FCT) under the scope of the research project PTDC/ AAG-TEC/5269/2014, the strategic funding of UID/BIO/04469/2013 unit and COMPETE 2020 (POCI-01-0145-FEDER-006684) and BioTecNorte operation (NORTE-01-0145-FEDER-000004) funded by the European Regional Development Fund under the scope of Norte2020 - Programa Operacional Regional do Norte.

\section{References}

1] N. Tahri Joutey, W. Bahafid, H. Sayel, H. Maâtaoui, F. Errachidi, N. El Ghachtouli, Use of experimental factorial design for optimization of hexavalent chromium removal by a bacterial consortium: soil microcosm bioremediation, Soil Sediment Contam. Int. J. 24 (2015) 129-142, https://doi.org/10.1080/15320383.2014. 922931.

[2] V.K. Gupta, a. Rastogi, Biosorption of hexavalent chromium by raw and acid-treated green alga Oedogonium hatei from aqueous solutions, J. Hazard. Mater. 163 (2009) 396-402, https://doi.org/10.1016/j.jhazmat.2008.06.104.

[3] G. Bayramoğlu, G. Çelik, E. Yalçin, M. Yilmaz, M.Y. Arica, Modification of surface properties of lentinus sajor-caju mycelia by physical and chemical methods: evaluation of their $\mathrm{Cr} 6++$ removal efficiencies from aqueous medium, J. Hazard. Mater. 119 (2005) 219-229, https://doi.org/10.1016/j.jhazmat.2004.12.022.

[4] Z. Zaroual, H. Chaair, A.H. Essadki, K. El Ass, M. Azzi, Optimizing the removal of trivalent chromium by electrocoagulation using experimental design, Chem. Eng. J. 148 (2009) 488-495, https://doi.org/10.1016/j.cej.2008.09.040.

[5] A. Santhana Krishna Kumar, S.J. Jiang, T. Wei Lung, Effective adsorption of chromium(VI)/Cr(III) from aqueous solution using ionic liquid functionalized mulitwalled carbon nanotube as a super sorbent, J. Mater. Chem. A 3 (2015) 7044-7057, https://doi.org/10.1039/C4TA06948J.

[6] D. Pradhan, L.B. Sukla, M. Sawyer, P.K.S.M. Rahman, Recent bioreduction of hexavalent chromium in wastewater treatment: a review, J. Ind. Eng. Chem. 55 (2017) 1-20, https://doi.org/10.1016/j.jiec.2017.06.040.

[7] W. Bahafid, N. Tahri Joutey, H. Sayel, M. Iraqui-Houssaini, N. El Ghachtouli, Chromium adsorption by three yeast strains isolated from sediments in Morocco, Geomicrobiol. J. 30 (2013) 422-429, https://doi.org/10.1080/01490451.2012. 705228.

[8] F. Veglio', F. Beolchini, Removal of metals by biosorption: a review, Hydrometallurgy 44 (1997) 301-316, https://doi.org/10.1016/S0304-386X(96) 00059-X.

[9] V.B.H. Dang, H.D. Doan, T. Dang-Vu, A. Lohi, Equilibrium and kinetics of biosorption of cadmium(II) and copper(II) ions by wheat straw, Bioresour. Technol. 100 (2009) 211-219, https://doi.org/10.1016/j.biortech.2008.05.031.

[10] J. Ye, H. Yin, B. Mai, H. Peng, H. Qin, B. He, N. Zhang, Biosorption of chromium from aqueous solution and electroplating wastewater using mixture of Candida lipolytica and dewatered sewage sludge, Bioresour. Technol. 101 (2010) 3893-3902, https://doi.org/10.1016/j.biortech.2010.01.014.

[11] D. Hoh, S. Watson, E. Kan, Algal biofilm reactors for integrated wastewater treatment and biofuel production: a review, Chem. Eng. J. 287 (2016) 466-473, https:// doi.org/10.1016/j.cej.2015.11.062.

[12] C. Quintelas, Z. Rocha, B. Silva, B. Fonseca, H. Figueiredo, T. Tavares, Removal of $\mathrm{Cd}(\mathrm{II}), \mathrm{Cr}(\mathrm{VI}), \mathrm{Fe}(\mathrm{III})$ and $\mathrm{Ni}(\mathrm{II})$ from aqueous solutions by an $E$. coli biofilm supported on kaolin, Chem. Eng. J. 149 (2009) 319-324, https://doi.org/10.1016/j cej.2008.11.025.

[13] C. Quintelas, R. Pereira, E. Kaplan, T. Tavares, Removal of Ni(II) from aqueous solutions by an Arthrobacter viscosus biofilm supported on zeolite: from laboratory to pilot scale, Bioresour. Technol. 142 (2013) 368-374, https://doi.org/10.1016/j biortech.2013.05.059.

[14] Z. Zainul Akmar, Z. Zainoha, S. Salmijah, A. Wan Azlina, Biological detoxification of $\mathrm{Cr}(\mathrm{VI})$ using wood-husk immobilized Acinetobacter haemolyticus, J. Hazard. Mater. 148 (2007) 164-171, https://doi.org/10.1016/j.jhazmat.2007.02.029.

[15] A. Abdolali, W. Guo, H. Ngo, S. Chen, N. Nguyen, K. Tung, Typical lignocellulosic wastes and by-products for biosorption process in water and wastewater treatment: a critical review, Bioresour. Technol. 160 (2014) 57-66, https://doi.org/10.1016/j. biortech.2013.12.037

[16] S. Elabed, M. Mostakim, F. Berguadi, H. Latrache, A. Houari, F. Hamadi, S. Ibnsouda Koraichi, Study of microbial adhesion on some wood species: theoretical prediction, Microbiology 80 (2011) 43-49, https://doi.org/10.1134/S0026261711010152.

[17] S. Elabed, S. Ibnsouda Koraichi, A. Houari, H. Latrache, Experimental and theoretical investigations of the adhesion time of Penicillium spores to cedar wood surface, Mater. Sci. Eng. C. Mater. Biol. Appl. 33 (2013) 1276-1281, https://doi.org/ 10.1016/j.msec.2012.12.026.

[18] M.F. Sailer, V.E.J. Nieuwenhuijzen, W. Knol, Forming of a functional biofilm on wood surfaces, Ecol. Eng. 36 (2010) 163-167, https://doi.org/10.1016/j.ecoleng. 2009.02.004.

[19] M. Sadiki, S. Elabed, H. Barkai, F. Laachari, S. Ibnsouda Koraichi, The impact of Thymus vulgaris extractives on cedar wood surface energy: theoretical and experimental of Penicillium spores adhesion, Ind. Crops Prod. 77 (2015) 1020-1027, https://doi.org/10.1016/j.indcrop.2015.10.001.

[20] K.E. Eboigbodin, C.A. Biggs, Characterization of the extracellular polymeric substances produced by Escherichia coli using infrared spectroscopic, proteomic, and aggregation studies, Biomacromolecules 9 (2008) 686-695.

[21] C. Quintelas, V.B. da Silva, B. Silva, H. Figueiredo, T. Tavares, Optimization of production of extracellular polymeric substances by arthrobacter viscosus and their interaction with a $13 \mathrm{X}$ zeolite for the biosorption of $\mathrm{Cr}(\mathrm{VI})$, Environ. Technol. 32 (2011) 1541-1549, https://doi.org/10.1080/09593330.2010.543930.

[22] J.A. Morillo Pérez, R. Garcia-Ribera, T. Quesada, M. Aguilera, A. Ramos-cormenzana, M. Monteoliva-sànchez, Biosorption of heavy metals by the exopolysaccharide produced by Paenibacillus jamilae, World J. Microb. Biotechnol. 24 (2008) 2699-2704, https://doi.org/10.1007/s11274-008-9800-9.

[23] G.-P. Sheng, H.-Q. Yu, X.-Y. Li, Extracellular polymeric substances (EPS) of microbial aggregates in biological wastewater treatment systems: a review, Biotechnol. Adv. 28 (2010) 882-894, https://doi.org/10.1016/j.biotechadv.2010. 08.001 .

[24] D. Kavak, M. Demir, B. Başsayel, A.S. Anagün, Factorial experimental design for optimizing the removal of lead ions from aqueous solutions by cation exchange resin, Desalin. Water Treat. 51 (2013) 1712-1719, https://doi.org/10.1080/ 19443994.2012.714640.

[25] M. Kılıç, B.B. Uzun, E. Pütün, A.E. Pütün, Optimization of biodiesel production from castor oil using factorial design, Fuel Process. Technol. 111 (2013) 105-110, https://doi.org/10.1016/j.fuproc.2012.05.032.

[26] M. Ahmadi, F. Vahabzadeh, B. Bonakdarpour, E. Mofarrah, M. Mehranian, Application of the central composite design and response surface methodology to the advanced treatment of olive oil processing wastewater using Fenton's peroxidation, J. Hazard. Mater. 123 (2005) 187-195, https://doi.org/10.1016/j.jhazmat. 2005.03.042.

[27] N. Mohd-Al-Faisal, W.H.A. Wan Harun, F. Abdul Razak, An in vitro study on the anti-adherence effect of Brucea javanica and Piper betle extracts towards oral Candida, Arch. Oral Biol. 58 (2013) 1335-1342, https://doi.org/10.1016/j. archoralbio.2013.07.001.

[28] M. Asri, A. Elabed, N. El Ghachtouli, S.I. Koraichi, W. Bahafid, S. Elabed, Theoretical and experimental adhesion of yeast strains with high chromium removal potential, Environ. Eng. Sci. 34 (2017) 693-702, https://doi.org/10.1089/ ees.2016.0515.

[29] E. a Vogler, Structure and reactivity of water at biomaterial surfaces, Adv. Colloid Interface Sci. 74 (1998) 69-117, https://doi.org/10.1016/S0001-8686(97) 00040-7.

[30] C.J. Van Oss, Interfacial Forces in Aqueous media, Dekker, New york, 1996.

[31] A.M. Gallardo-moreno, M.L. González-Martín, C. Pérez-Giraldo, J.M. Bruque, A.C. Gómez-García, The measurement temperature: an important factor relating physicochemical and adhesive properties of yeast cells to biomaterials, J. Colloid Interface Sci. 271 (2004) 351-358, https://doi.org/10.1016/j.jcis.2003.12.008.

[32] H.H.M. Rijnaarts, W. Norde, J. Lyklema, A.J.B. Zehnder, DLVO and steric contributions to bacterial deposition in media of different ionic strengths, Colloids Surfaces B Biointerfaces 14 (1999) 179-195, https://doi.org/10.1016/S09277765(99)00035-1.

[33] W. Bahafid, H. Sayel, N. Tahri-Joutey, N. El Ghachtouli, Removal mechanism of hexavalent chromium by a novel strain of Pichia anomala isolated from industria effluents of fez (Morocco), J. Environ. Sci. Eng. 5 (2011) 980-991.

[34] P. Pattanapipitpaisal, N.L. Brown, L. Macaskie, Chromate reduction and 16S rRNA identification of bacteria isolated from a $\mathrm{Cr}(\mathrm{VI})$-contaminated site, Appl. Microbiol Biotechnol. 57 (2001) 257-261, https://doi.org/10.1007/s002530100758.

[35] M. De Meijer, S. Haemers, W. Cobben, H. Militz, Surface energy determinations of wood: comparison of methods and wood species, Langmuir 16 (2000) 9352-9359, https://doi.org/10.1021/la001080n.

[36] I. Mohammed-Ziegler, Á. Oszlánczi, B. Somfai, Z. Hórvölgyi, I. Pászli, A. Holmgren, W. Forsling, Surface free energy of natural and surface-modified tropical and European wood species, J. Adhes. Sci. Technol. 18 (2004) 687-713, https://doi. org/10.1163/156856104839338.

[37] L. Albert, Z.I. Németh, G. Halász, J. Koloszár, S. Varga, L. Takács, Radial variation of $\mathrm{pH}$ and buffer capacity in the red-heartwooded beech (Fagus silvatica L.) wood, Holz Als Roh - Und Werkst. 57 (1999) 75-76, https://doi.org/10.1007/ PL00002626.

[38] M.N. Chirwa Evans, Y.T. Wang, Chromium (VI) reduction by Pseudomonas fluorescens LB300 in fixed-film bioreactor, J. Environ. Eng. 123 (1997) 760-766.

[39] P. Gérardin, M. Petrič, M. Petrissans, J. Lambert, J.J. Ehrhrardt, Evolution of wood surface free energy after heat treatment, Polym. Degrad. Stab. 92 (2007) 653-657, https://doi.org/10.1016/j.polymdegradstab.2007.01.016.

[40] M. Mercier-Bonin, K. Ouazzani, P. Schmitz, S. Lorthois, Study of bioadhesion on a flat plate with a yeast/glass model system, J. Colloid Interface Sci. 271 (2004) 
342-350, https://doi.org/10.1016/j.jcis.2003.11.045.

[41] P.F.F. Amaral, M. Lehocky, Cell surface characterization of Yarrowia lipolytica, Wiley Intersci. 23 (2006) 867-877, https://doi.org/10.1002/yea.1405.

[42] G. Smit, M.H. Straver, B.E.N.J.J. Lugtenberg, J.A.N.W. Kijne, Flocculence of Saccharomyces cerevisiae cells is induced by nutrient limitation, with cell surface hydrophobicity as a major determinant, Appl. Environ. Microbiol. 58 (1992) 3709-3714.

[43] G. Suzzi, P. Romano, L. Vannini, Cell surface hydrophobicity and flocculence in Saccharomyces cerevisiae wine yeasts, Colloids Surf. B Biointerfaces 2 (1994) 505-510, https://doi.org/10.1016/0927-7765(94)80058-8.

[44] S. Vichi, J.J. Gallardo-Chacón, R. Pradelles, D. Chassagne, E. López-Tamames, S. Buxaderas, Surface properties of Saccharomyces cerevisiae lees during sparkling wine ageing and their effect on flocculation, Int. J. Food Microbiol. 140 (2010) 125-130, https://doi.org/10.1016/j.ijfoodmicro.2010.04.009.

[45] H.C. Van Der Mei, R. Bos, H.J. Busscher, A reference guide to microbial cell surface hydrophobicity based on contact angles, Colloids Surf. B Biointerfaces 11 (1998) 213-221, https://doi.org/10.1016/S0927-7765(98)00037-X.

[46] E.D. Amory, P.G. Rouxhet, Flocculence of brewery yeasts and their surface properties: chemical composition, electrostatic charge and hydrophobicity, J. Inst. Brew. 94 (1988) 79-84.

[47] B. Silva, H. Figueiredo, C. Quintelas, I.C. Neves, T. Tavares, Zeolites as supports for the biorecovery of hexavalent and trivalent chromium, Microporous Mesoporous Mater. 116 (2008) 555-560, https://doi.org/10.1016/j.micromeso.2008.05.015.

[48] C. Ferronato, B. Silva, F. Costa, T. Tavares, Vermiculite bio-barriers for $\mathrm{Cu}$ and $\mathrm{Zn}$ remediation: an eco-friendly approach for freshwater and sediments protection, Int. J. Environ. Sci. Technol. 13 (2016) 1219-1228, https://doi.org/10.1007/s13762016-0957-8.

[49] G. Bayramoğlu, M. Yakup Arica, Construction a hybrid biosorbent using Scenedesmus quadricauda and Ca-alginate for biosorption of $\mathrm{Cu}(\mathrm{II}), \mathrm{Zn}(\mathrm{II})$ and $\mathrm{Ni}(\mathrm{II})$ : kinetics and equilibrium studies, Bioresour. Technol. 100 (2009) 186-193, https:// doi.org/10.1016/j.biortech.2008.05.050.

[50] A.I. Zouboulis, M.X. Loukidou, K.A. Matis, Biosorption of toxic metals from aqueous solutions by bacteria strains isolated from metal-polluted soils, Process Biochem. 39 (2004) 909-916, https://doi.org/10.1016/S0032-9592(03)00200-0.

[51] M. Feng, X. Chen, C. Li, R. Nurgul, M. Dong, Isolation and identification of an exopolysaccharide-producing lactic acid bacterium strain from Chinese paocai and biosorption of $\mathrm{Pb}(\mathrm{II})$ by its exopolysaccharide, J. Food Sci. 77 (2012), https://doi. org /10.1111/j.1750-3841.2012.02734.x.

[52] A. Esposito, F. Pagnanelli, F. Vegliò, pH-related equilibria models for biosorption in single metal systems, Chem. Eng. Sci. 57 (2002) 307-313, https://doi.org/10.1016/ S0009-2509(01)00399-2.

[53] R.S. Bai, T.E. Abraham, Studies on enhancement of $\mathrm{Cr}(\mathrm{VI})$ biosorption by chemically modified biomass of Rhizopus nigricans, Water Res. 36 (2002) 1224-1236, https://doi.org/10.1016/S0043-1354(01)00330-X.

[54] C. Quintelas, Z. Rocha, B. Silva, B. Fonseca, H. Figueiredo, T. Tavares, Removal of $\mathrm{Cd}(\mathrm{II}), \mathrm{Cr}(\mathrm{VI}), \mathrm{Fe}(\mathrm{III})$ and $\mathrm{Ni}(\mathrm{II})$ from aqueous solutions by an $E$. coli biofilm supported on kaolin, Chem. Eng. J. 149 (2009) 319-324, https://doi.org/10.1016/j. cej.2008.11.025.

[55] M.A. Hanif, R. Nadeem, M.N. Zafar, K. Akhtar, H.N. Bhatti, Kinetic studies for Ni(II) biosorption from industrial wastewater by Cassia fistula (Golden Shower) biomass, J. Hazard. Mater. 145 (2007) 501-505, https://doi.org/10.1016/j.jhazmat.2007. 01.022.

[56] D. Park, Y.S. Yun, J.H. Jo, J.M. Park, Mechanism of hexavalent chromium removal by dead fungal biomass of Aspergillus niger, Water Res. 39 (2005) 533-540, https:// doi.org/10.1016/j.watres.2004.11.002.

[57] T. Stephenson, E. Reid, L.M. Avery, B. Jefferson, Media surface properties and the development of nitrifying biofilms in mixed cultures for wastewater treatment, Process Saf. Environ. Prot. 91 (2013) 321-324, https://doi.org/10.1016/j.psep. 2012.07.002.

[58] Z. Lewandowski, Biofilms in Water and Wastewater Treatment, (2011), pp. 529-567.

[59] T.V.N. Padmesh, K. Vijayaraghavan, G. Sekaran, M. Velan, Biosorption of acid blue 15 using fresh water macroalga Azolla filiculoides: batch and column studies, Dyes Pigm. 71 (2006) 77-82, https://doi.org/10.1016/j.dyepig.2005.06.003.

[60] C. Quintelas, B. Fernandes, J. Castro, H. Figueiredo, T. Tavares, Biosorption of Cr (VI) by a Bacillus coagulans biofilm supported on granular activated carbon (GAC), Chem. Eng. J. 136 (2008) 195-203, https://doi.org/10.1016/j.cej.2007.03.082.

[61] A.H. Hawari, C.N. Mulligan, Heavy metals uptake mechanisms in a fixed-bed column by calcium-treated anaerobic biomass, Process Biochem. 41 (2006) 187-198, https://doi.org/10.1016/j.procbio.2005.06.018.

[62] G.R. Petersen, G.A. Nelson, C.A. Cathey, G.G. Fuller, Rheologically interesting polysaccharides from yeasts, Appl. Biochem. Biotechnol. 20-21 (1989) 845-867, https://doi.org/10.1007/BF02936530.

[63] A.G. González, L.S. Shirokova, O.S. Pokrovsky, E.E. Emnova, R.E. Martínez, J.M. Santana-Casiano, M. González-Dávila, G.S. Pokrovski, Adsorption of copper on Pseudomonas aureofaciens: protective role of surface exopolysaccharides, J. Colloid Interface Sci. 350 (2010) 305-314, https://doi.org/10.1016/j.jcis.2010.06.020.

[64] S.K. Kazy, P. Sar, S.P. Singh, A.K. Sen, S.F. D’Souza, Extracellular polysaccharides of a copper-sensitive and a copper-resistant Pseudomonas aeruginosa strain: synthesis, chemical nature and copper binding, World J. Microbiol. Biotechnol. 18 (2002) 583-588.

[65] M. Ueshima, B.R. Ginn, E.A. Haack, J.E.S. Szymanowski, J.B. Fein, Cd Adsorption onto Pseudomonas putida in the presence and absence of extracellular polymeric substances, Geochim. Cosmochim. Acta 72 (2008) 5885-5895, https://doi.org/10. 1016/j.gca.2008.09.014.

[66] M.E. Davey, G.A. O'toole, Microbial biofilms: from ecology to molecular genetics, Microbiol. Mol. Biol. Rev. 64 (2000) 847-867, https://doi.org/10.1128/MMBR.64. 4.847-867.2000.

[67] D. Cozzi, P.G. Desideri, L. Lepri, The mechanism of ion Exchange with alginic acid, J. Chromatogr. 40 (1968) 130-137.

[68] S.A. Kimmel, R.F. Roberts, Development of a growth medium suitable for exopolysaccharide production by Lactobacillus delbrueckii ssp. bulgaricus RR, Int. J. Food Microbiol. 40 (1998) 87-92, https://doi.org/10.1016/S0168-1605(98)00023-3.

[69] J. Tourney, B.T. Ngwenya, J.W. Fred Mosselmans, M. Magennis, Physical and chemical effects of extracellular polymers (EPS) on Zn adsorption to Bacillus licheniformis S-86, J. Colloid Interface Sci. 337 (2009) 381-389, https://doi.org/10. 1016/j.jcis.2009.05.067. 